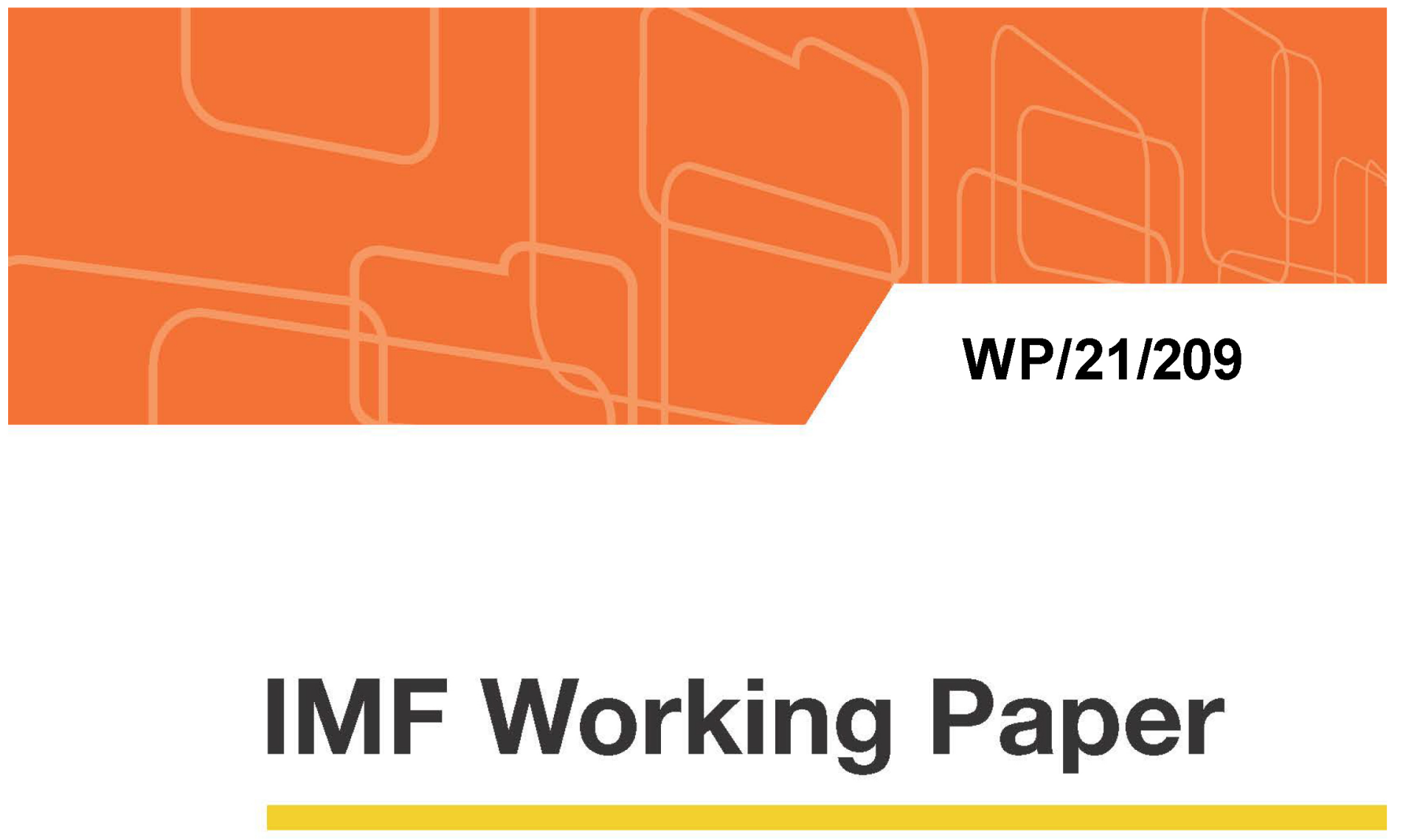

\title{
Unintended Consequences of U. S. Monetary Policy Shocks: Dutch Disease and Capital Flow Measures in Emerging Markets and Developing Economies
}

\author{
by Juan F. Yépez
}

IMF Working Papers describe research in progress by the author(s) and are published to elicit comments and to encourage debate. The views expressed in IMF Working Papers are those of the author(s) and do not necessarily represent the views of the IMF, its Executive Board, or IMF management. 


\title{
IMF Working Paper
}

\author{
Strategy, Policy, and Review Department
}

\section{Unintended Consequences of U. S. Monetary Policy Shocks: Dutch Disease and Capital Flow Measures in Emerging Markets and Developing Economies}

\author{
Prepared by Juan F. Yépez. ${ }^{1}$ \\ Authorized for distribution by Martin Čihák
}

July 2021

IMF Working Papers describe research in progress by the author(s) and are published to elicit comments and to encourage debate. The views expressed in IMF Working Papers are those of the author(s) and do not necessarily represent the views of the IMF, its Executive Board, or IMF management.

\begin{abstract}
Dutch disease is often referred as a situation in which large and sustained foreign currency inflows lead to a contraction of the tradable sector by giving rise to a real appreciation of the home currency. This paper documents that this syndrome has been witnessed by many emerging markets and developing economies (EMDEs) as a result of surges in capital inflows driven by accommodative U. S. monetary policy. In a sample of 25 EMDEs from 2000-17, U. S. monetary policy shocks coincided with episodes of currency appreciation and a contraction in tradable output in these economies. The paper also shows empirically that the use of capital flow measures (CFMs) has been a common policy response in several EMDEs to U.S. monetary policy shocks. Against this background, the paper presents a two sector small open economy augmented with a learning-by-doing (LBD) mechanism in the tradable sector to rationalize these empirical findings. A welfare analysis provides a rationale for the use of CFMs as a second-best policy when agents do not internalize the LBD externality of costly resource misallocation as a result of greater capital inflows. However, the adequate calibration of CFMs and the quantification of the LBD externality represent important implementation challenges.
\end{abstract}

JEL Classification Numbers: E52, F41.

Keywords: CFMs, Dutch Disease, U.S. Monetary Policy Shocks, Learning-by-Doing. Author’s E-Mail Address: jyepezalbornoz@imf.org

\footnotetext{
${ }^{1}$ I am grateful to Martin Cihák and Fabián Valencia for helpful discussions. I also thank Bas Bakker, Francesco Grigoli, Marcin Kolasa, Valerie Lankester, Nicolás Magud, Gabor Meizer, Jorge Roldós and seminar participants at the IMF for helpful comments. All remaining errors are my own.
} 


\section{INTRODUCTION}

Ultra-accommodative monetary policies in advanced economies, particularly in the United States, have had considerable spillover effects on emerging economies (Rey, 2013; KalemliÖzcan, 2019). Investors, in search of a higher yield, shifted their portfolios to many emerging markets and developing economies (EMDEs) in higher proportions during the past decade and a half (Figure 1). While the greater availability of foreign capital during episodes of accommodative U.S. monetary policy supported growth through better risk sharing and increased technology transfer, the sheer magnitude and cyclical nature of these transactions amplified domestic imbalances and left several EMDEs more vulnerable to foreign shocks. Given the uncertainty over the sustainability of capital inflows, EMDEs have defensively accumulated reserves and in several cases resorted to capital flow management measures (CFMs). ${ }^{1}$

Figure 1. Non-Resident Capital Inflows to Selected EMDEs and U.S. Shadow Policy Rate

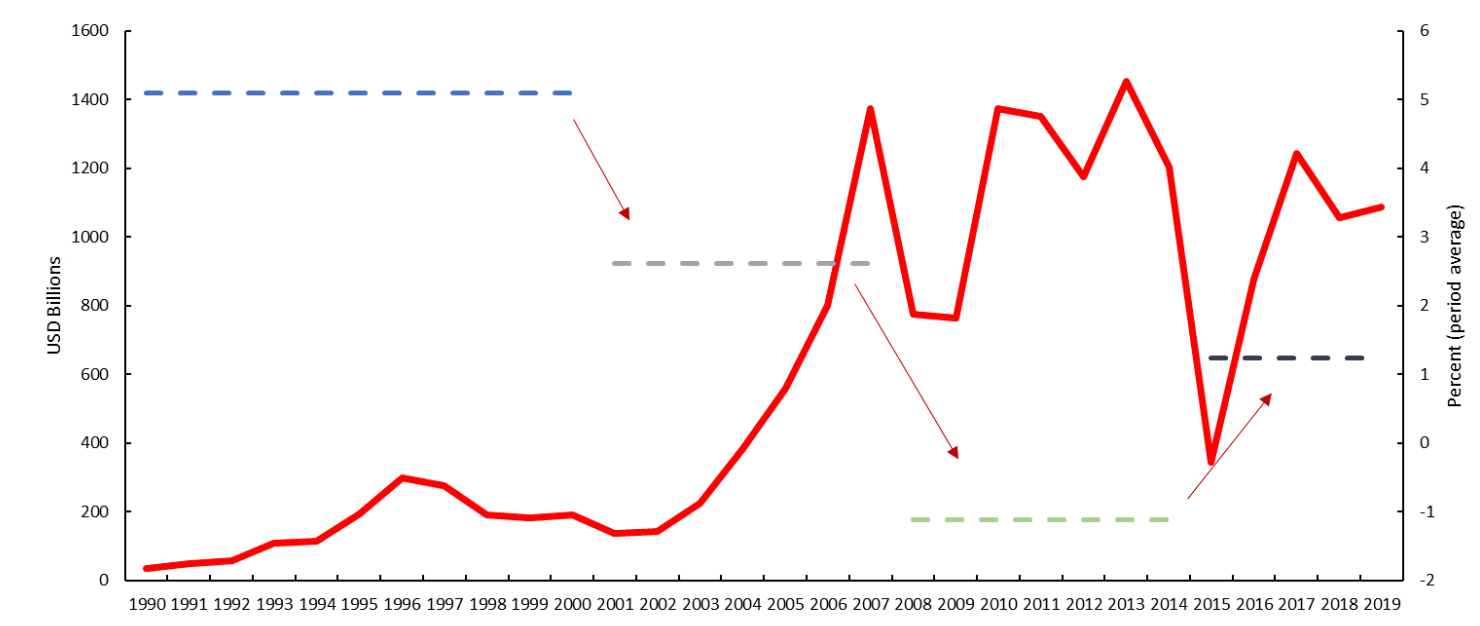

Capital Inflows (left axis) - - Shadow US Policy Rate (1990-2000) - - Shadow US Policy Rate (2001-07) - - Shadow US Policy Rate (2008-14) — - Shadow US Policy Rate (2015-19)

Source: IIF, Wu and Xia (2016), and Haver Analytics. Note: the horizontal dashed lines represents the period average of the Wu Xia (2016) shadow U.S. federal funds rate. The four periods illustrated are the pre dot-com bubble crash (1990-2000); the pre-GFC (2001-07); post-GFC (2008-14); and U.S. policy liftoff period (2015-19). The Wu and Xia (2016) shadow federal funds rate is a proxy for the U. S. monetary policy rate, it accounts for the zero lower bound and the macroeconomic effects of unconventional monetary policy in the United States after the GFC.

Given the increased prevalence in the use of CFMs across EMDEs over the past two decades (Fernandez and others, 2013), studies have focused on an externality view of CFMs in order to justify the use of these policy tools. ${ }^{2}$ The common theme of this strand of literature is

\footnotetext{
${ }^{1}$ See Forbes, Fratzscher, and Straub (2015).

${ }^{2}$ See Erten, Korinek, and Ocampo (2021) for a detailed overview of the "externality" literature on CFMs.
} 
that capital flows may generate externalities that private agents do not internalize, with the externalities emphasized by this work being mainly financial in nature. The presence of these externalities induce private agents to borrow too much (ex-ante), to buy too little insurance or take on excessive risk, and to borrow excessively short term. However, a recent strand of the literature has started to look at the implications of capital inflows on the allocation of resources across industries (Reis, 2013; Benigno, Converse, and Fornaro, 2015; Saffie, Varela, and $\mathrm{Yi}, 2020$ ). This literature links inflows to a contraction (expansion) of the tradable (nontradable) sector by giving rise to a real appreciation of the home currency, a situation often referred to as Dutch disease.

This paper seeks to examine the merits of the use of CFMs as a policy intervention tool to alleviate possible Dutch disease effects stemming from capital inflows. Specifically, the paper makes three contributions: $i$ ) it empirically documents that Dutch disease in EMDEs was a common side effect of U. S. monetary policy shocks; $i$ ) the paper shows that the use of CFMs in response to U.S. interest rate shocks was common and generalized across these economies; and iii) the paper rationalizes these empirical findings in a dynamic stochastic general equilibrium (DSGE) model and evaluates the welfare implications of using CFMs to prevent costly resource misallocation as a result of Dutch disease. ${ }^{3}$

To document the presence of Dutch disease episodes, the empirical section of the paper estimates the effects of U. S. monetary policy shocks on the currencies and tradable output of a sample of 25 EMDEs. The empirical strategy is centered around U. S. monetary policy shocks as these have been the main drivers of capital flows by non-residents to EMDEs (see Milesi-Ferretti and Tille, 2011; Shin, 2012; Rey, 2013; among others). Also, U. S. monetary policy can be assumed to be exogenous to innovations in the currencies and tradable output of EMDEs, which allows for a more precise statistical identification of the spillover effect of these policy shocks on EMDEs.

The paper also documents the evolution of restrictions to capital account transactions following U. S. monetary policy shocks. It does so by exploiting a set of measures of capital account restrictions developed by Fernández and others (2016). ${ }^{4}$ Given the inherent endogeneity of CFMs, the effects of U. S. monetary policy shocks on EMDEs are estimated within a system of regressions using a panel vector auto-regression (PVAR) framework. The CFM index is treated as an endogenous variable in this framework. Results are summarized in the form of impulse responses within a five year horizon.

The results suggest that U.S. monetary policy shocks led to statistically significant Dutch disease effects in EMDEs in the last decade and a half. One year after a one percentage point re-

\footnotetext{
${ }^{3}$ The term "Dutch disease" was first introduced by the Economist in 1977 to describe the economic crisis in the Netherlands in the 1960s following the discovery of North Sea natural gas deposits. More recently, the term is also used to describe the effects on the tradable sector induced by remittances, foreign aid, terms-of-trade shocks and capital inflows (see Kojo, 2014).

${ }^{4}$ This index uses information from the IMF's Annual Report on Exchange Arrangements and Exchange Restrictions (AREAER). This is one of the few indices that distinguishes between CFMs on inflows and outflows and provides a unified framework to measure the intensity of CFMs across countries.
} 
duction in the U. S. monetary policy rate, currencies appreciate significantly and the share of tradable output in total GDP decline by around half a percentage point. The currency appreciation is somewhat temporary, but the decline in tradable output is relatively more persistent. In terms of policy response, EMDEs tend to increase the number of capital flow restrictions on inflows after U. S. monetary policy shocks, with the tightening of CFMs in some cases lasting for several years. Robustness exercises suggest that Dutch disease effects were more significant in EMDEs with more flexible exchange rates and during the post global financial crisis period. While the paper does not find evidence of Dutch disease effects in AEs, the use of CFMs in these economies was common during periods of more accommodative U. S. monetary policy. These results are also robust to alternative measures of U. S. monetary policy shocks.

Against the backdrop of these empirical findings on how U. S. monetary policy shocks gave rise to Dutch disease effects and the use of CFMs in EMDEs, the paper seeks to explore whether the use of CFMs limited to some extent the currency appreciation and contraction of the tradable sector in EMDEs. In order to assess the appropriateness and optimality of the use of CFMs in response to U.S. monetary policy shocks to avoid Dutch disease effects, the empirical findings are qualitatively matched using a dynamic stochastic general equilibrium (DSGE) model. ${ }^{5}$

The DSGE model consists of a representative household and two sectors (tradable and nontradable). Households have access to international credit markets, but they are subject to a tax on interest rate payments (i.e., a CFM) on external debt (as in Kitano, 2011). The model is based on a small open economy assumption, that is that households take the interest rate on foreign debt as given and firms have no effect on the price of tradable goods. As in the empirical analysis, impulse responses are calculated for a negative shock to the global interest rate. To assess the welfare implications of using CFMs to limit Dutch disease effects, model simulations are conducted for various tax rates on foreign debt service.

Results from the model simulations suggest that there is indeed a role for CFMs in limiting Dutch disease following a shock to the global interest rate. A tax on foreign debt service raises the cost of foreign capital and discourages foreign borrowing. The lower availability of foreign capital in turn attenuates the appreciation of the currency and a reallocation of resources from the tradable to the non-tradable sector. This effect is achieved by limiting the increase in the relative price of non-tradables (as compared to a regime with no CFMs). Against this background, the model does a good job in qualitatively matching Dutch disease effects arising from a sudden reduction in the U.S. monetary policy rate observed in the data and showing how CFMs could limit these effects in a small open economy.

In a standard frictionless two-sector real business-cycle model, the reallocation between the tradable and non-tradable sector, such as the one described above, is the efficient response to

\footnotetext{
${ }^{5} \mathrm{~A}$ number of authors have call into question the merits of DSGE models in policy analysis (see Blanchard 2018 and the discussion therein). However, a data based DSGE model is a powerful tool to illustrate the effects of a well identified exogenous shock and to assess the effects of a systematic policy change (see Christiano, Eichenbaum, and Trabandt, 2018).
} 
an increase in the availability of foreign capital. Higher credit access following a reduction in global interest rates will increase the demand for tradable and non-tradable goods, and as a consequence wages will be higher in the economy. Since the model takes international prices as given, higher wages will reduce the production of tradable goods, and the demand will be satisfied with imports from the rest of the world. In this situation there is no rationale for government intervention, and protecting the tradable sector will reduce overall welfare.

A common friction commonly discussed in the Dutch disease literature, and the focus of the theoretical section in this paper, is a learning-by-doing (LBD) externality in the tradable sector. The LBD technology augments the productivity of the tradable sector, and represents a cost to the reallocation of resource away from this sector. By augmenting the model to include an LBD mechanism, a reduction in tradable output will lead to lower productivity in that sector and a decrease of future production. If this mechanism is not internalized by the firms, then there will be an inefficient loss of tradable production and hence a role for policy intervention. This paper focuses on the merits of CFMs as a second-best policy in the presence of an LBD externality. ${ }^{6}$

One of the main insights of this paper is that the use of CFMs on inflows could be a welfareincreasing policy to counteract the effects of the Dutch disease in the presence of an LBD externality. By preventing a large appreciation of the currency stemming from surges in capital inflows generated by U.S. monetary policy shocks, CFMs can prevent a contraction of tradable production below the efficient level. Under standard calibration parameters, the theoretical analysis of the paper finds that limiting the increase in the relative price of nontradables prevents an inefficient reallocation of resources away from the tradable sector, with this in turn leading to higher total output in the long-term and to an increase in households' welfare. These conclusions are robust to different levels of the LBD externality.

The importance of an LBD externality hinges on the assumption that the tradable sector is the sole contributor to LBD, which may clearly be a realistic approximation for some EMDEs, and equally unrealistic for others. In this regard the use of CFMs to address Dutch disease effects would be most suitable for EMDEs with a sizable manufacturing export sector, a sector identified in the literature as the one in which LBD accrues the most. However, the use of CFMs could be subject to trade-offs. While policies aimed at preventing surges in capital inflows could be appropriate in the presence of an LBD externality, they could amplify macroeconomic volatility in the presence of other frictions, such as nominal rigidities in other sectors. However, given that in many EMDEs monetary policy frameworks are still evolving and inflation expectations are not strongly anchored, policies that enable policymakers in these economies to avoid sharp currency fluctuations and prevent undue losses in tradable output are likely to dominate other policy alternatives.

The results presented in this paper also highlight that there are important implementation challenges, as the benefits of CFMs could be large but for a narrow region of the tax. This

\footnotetext{
${ }^{6}$ The first best (i.e., the social planner's) solution would be the one in which the externality is removed and agents internalize the cost of resource reallocation.
} 
means that policymakers need to carefully calibrate the magnitude of CFMs, otherwise the gains from these policies become very small. Furthermore, the fact that the LBD externality is not observable and difficult to measure, calibrating an appropriate CFM response (not only regarding their magnitude but also their duration) could be a challenging endeavor for policymakers.

Related literature. The empirical section of the paper adds to a relatively recent literature documenting that in middle income economies, expansions owing to capital inflows lead to resources shifting away from tradable activities (see, for example, Tornell and Westermann 2005; Reis 2013; Benigno, Converse, and Fornaro 2015; Saffie and others 2019). Few papers have empirically examined the role of CFMs in insulating countries from external shocks in a multi-country setting, but usually treating CFMs as exogenous random variables. Miniane and Rogers (2007) and Bergant and others (2020), for example, condition the response of output to external shocks depending on the intensity of CFMs and conclude that CFMs are not effective in insulating output from global shocks. However, it could be argued that not accounting for the endogeneity of CFMs can give rise to treatment bias, as CFMs are likely to be used in response to external and domestic macroeconomic conditions.

This paper extends the above empirical analyses on sectoral resource allocations of capital inflows and the insulating role of CFMs by extending the analysis to a larger set of EMDEs and by treating CFMs as an endogenous variable with a PVAR framework. Also, in contrast to the above empirical research, this paper highlights the Dutch disease effects that could arise from global financial shocks, as the contraction in tradable output following surges in capital inflows could come as a result of appreciation of the home currency.

The paper is also related to an extensive Dutch disease literature (see, for example, Magud and Sosa, 2013, for a detailed survey). Work in this literature has focused on the reallocation of resources away from the tradable non-commodity sectors, usually as a result of termsof-trade shocks. The most common friction used to generate the misallocation of resources in response to a currency appreciation is an LBD externality in the tradable sector (see, for example, Van Wijnbergen 1984; Krugman 1987; Caballero and Lorenzoni 2014).

Only in the last decade there have been some development of papers dealing with policy responses to Dutch disease, but focused mainly on terms-of-trade shifts generated by commodity price shocks. Our paper follows closely Lama and Medina (2012), which constructs a New Keynesian model with an explicit commodity exporting sector and an LBD externality in the non-commodity export sectors to analyze the macroeconomic and welfare effects of exchange-rate stabilization policies. Our paper departs from this literature by examining instead Dutch disease effects arising from shocks to global interest rates in a real business cycle model and by examining explicitly the role of CFMs as a policy response.

Finally, the paper contributes to the large literature on the optimality of CFMs as a policy option. This literature has focused mainly on pecuniary externalities associated with financial instability (for this literature see Bianchi 2011 and a survey by Erten, Korinek, and Ocampo, 
2021) and aggregate demand externalities due to nominal rigidities, associated with unemployment (see Schmitt-Grohe and Uribe 2016 and Farhi and Werning 2012). Recent papers have incorporated these externalities within a framework to analyze the interaction of CFMs with monetary policy, foreign exchange intervention, and macroprudential policy (see Basu and others 2020 and Adrian and others, 2020). This paper adds to this literature by looking at the merits of CFMs in a DSGE model with frictions in the real sector in the form of costly resource misallocation.

The paper is organized as follows. Section 2 describes the empirical analysis. Section 3 presents the model and the quantitative analysis of the role of CFMs in limiting Dutch disease. Section 4 concludes.

\section{EMPIRICS}

This section presents empirical evidence on the presence of Dutch disease effects in EMDEs following episodes of sharp reductions in the U.S. policy rate and the usage of CFMs in response to these exogenous shocks. The analysis is based on a PVAR framework with block exogeneity restrictions and variables in the system ordered in recursive order. Data is obtained from publicly available sources for a panel of 25 EMDEs at an annual frequency from 2000 until 2017. Results of the effects of a one percentage point reduction in the U.S. policy rate are summarized in the form of cumulative impulse responses at a five year horizon. Results are robust if the sample is expanded to include small and open advanced economies, if it censored to include only post-GFC period, and by conditioning the responses to different exchange rate regimes.

\section{A. Data}

This paper analyzes the effects of a U. S. monetary policy shocks in a sample of 25 EMDEs that have experienced reversals in their paths toward financial account liberalization over the 2000 to 2017 time period. $^{7}$ The sample selection and time period of the analysis are based on data availability for the different variables used in the analysis. The selected sample represents around 80 percent of total GDP of EMDEs according to the IMF's World Economic Outlook data.

This paper addresses the inherent endogeneity of CFMs by including an index of the intensity of capital controls in the econometric analysis. The index employed, which is one of the few that distinguishes between CFMs on inflows and outflows, is a set of measures on capital control restrictions developed by Fernandez and others (2016). This index uses information from

\footnotetext{
${ }^{7}$ The sample consists of the following economies: Argentina, Brazil, Bulgaria, Chile, China, Colombia, Costa Rica, Egypt, Guatemala, Hungary, India, Indonesia, Kazakhstan, Malaysia, Mexico, Pakistan, Paraguay, Peru, Philippines, Poland, Romania, Russia, South Africa, Turkey, and Ukraine.
} 
the IMF's Annual Report on Exchange Arrangements and Exchange Restrictions (AREAER). The index provides a unified framework to measure the intensity of inflow CFMs across countries, thereby allowing to compare the use of CFMs in a multi-country setting. In this regard, the empirical section seeks to document that CFMs have been used often across EMDEs in the last two decades.

The variables associated with Dutch disease effects are tradable output and the real exchange rate. For tradable output, the paper uses the share of manufacturing value added in GDP, as this is the most commonly used measure in the Dutch disease literature (Rajan and Subramanian, 2011). The data comes from the World Bank's WDI database and Eurostat. The importance of manufacturing value added in GDP varies across EMDEs (Figure 2), with the share of manufacturing in total output being the highest in non-commodity exporting EMDEs (representing around 20 percent of GDP). While capital inflows are the deep determinant of Dutch disease effects, the exchange rate is the proximate transmission mechanism. The paper uses a CPI based real effective exchange rate (REER) obtained from the IMF's Information Notice System.

Figure 2. Share of Manufacturing Value Added in GDP in Selected EMDEs, 2019 (In percent)

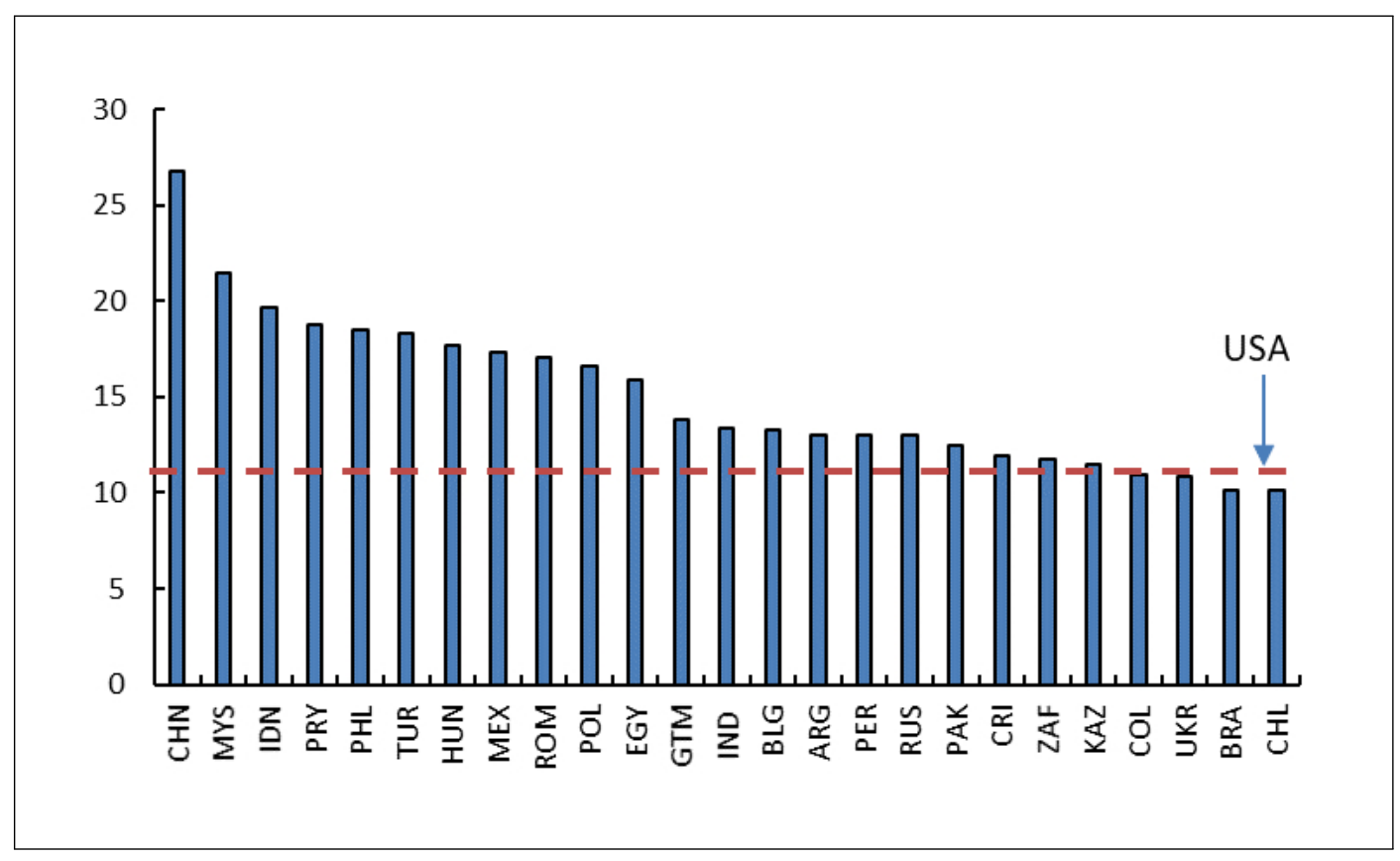

Source: World Bank, World Development Indicators and Eurostat.

Finally, the paper uses the $\mathrm{Wu}$ and Xia (2016) shadow federal funds rate as a proxy for the U. S. monetary policy rate, which helps to account for periods when the policy rate reached the zero lower bound in the United States after the global financial crisis. The data is for the end of period and obtained from Haver Analytics. 


\section{B. PVAR Framework}

The empirical strategy is based on a PVAR for 25 EMDEs, which seeks to capture the dynamic response of the REER, tradable output, and inflows CFMs to U. S. monetary policy shocks. Simultaneity issues are addressed in the identification of the empirical model by assuming that countries take innovations in U. S. monetary policy as exogenously given, i.e. variations in the U.S. shadow federal funds rate can be regarded as an exogenous source of aggregate fluctuations in EMDEs. To fix ideas, the PVAR system can be written (abstracting from the intercept) as:

$$
\left(\begin{array}{cccc}
1 & 0 & 0 & 0 \\
a_{i, 2,1} & 1 & a_{i, 2,3} & a_{i, 2,4} \\
a_{i, 3,1} & a_{i, 3,2} & 1 & a_{i, 3,4} \\
a_{i, 4,1} & a_{i, 4,2} & a_{i, 4,3} & 1
\end{array}\right)\left[\begin{array}{c}
\Delta F F R_{t} \\
\Delta C F M_{i, t} \\
\Delta R E E R_{i, t} \\
\Delta Y_{i, t}
\end{array}\right]=\sum_{j=1}^{p} A_{i, j}\left[\begin{array}{c}
\Delta F F R_{t-j} \\
\Delta C F M_{i, t-j} \\
\Delta R E E R_{i, t-j} \\
\Delta Y_{i, t-j}
\end{array}\right]+\left[\begin{array}{c}
\varepsilon_{t}^{1} \\
\varepsilon_{i, t}^{2} \\
\varepsilon_{i, t}^{3} \\
\varepsilon_{i, t}^{4}
\end{array}\right]
$$

where $\triangle F F R_{t}$ is the one-year change in the Wu and Xia (2016) shadow U.S. federal funds rate, $\triangle C F M_{i, t}$ is the one-year change in CFM index, $\triangle R E E R_{i, t-j}$ is the log one-year change in the REER, and $\Delta Y_{i, t-j}$ is the log one year change in the ratio of manufacturing output to total GDP. The lag length is denoted by $\mathrm{p}$. The structural shocks are denoted by $\varepsilon_{i, t}^{k}$ with $k \in[1,2$, $3,4]$. The U. S. monetary policy shock is denoted by $\varepsilon_{t}^{1}$.

The exogeneity of U. S. monetary policy and a recursive ordering of the EMDE variables are sufficient assumptions to identify the model. The assumption that monetary policy in the United States does not react to developments in EMDEs identifies $a_{i, 2,1}, a_{i, 3,1}$, and $a_{i, 4,1}$. Also, given the block exogeneity assumption, the dynamic effects of U. S. monetary policy shocks will be independent of the ordering of the EMDE variables in the PVAR. The recursive ordering sets $a_{i, 2,3}=a_{i, 2,4}=a_{i, 3,4}=0$, which amounts to using a Cholesky decomposition of the system. Once these restrictions are imposed and the impact matrix $\left(A_{i, 0}\right)$ is inverted, the structural form of the system specified in equation (1) above can be written as (again abstracting from country-specific intercepts):

$$
Y_{i, t}=\sum_{j=1}^{p} A_{i, 0}^{-1} A_{i, j} Y_{i, t-1}+A_{i, 0}^{-1} \varepsilon_{i, t}
$$

where $Y_{i, t}=\left[\Delta F F R_{t} \Delta C F M_{i, t} \Delta R E E R_{i, t} \Delta Y_{i, t}\right]^{\prime}$. This can be written more compactly in companion matrix form as a $\operatorname{VAR}(1)$ by defining $Z_{i, t}=\left[\begin{array}{llll}y_{i, t} & y_{i, t-1} & \ldots & y_{i, t-p}\end{array}\right]^{\prime}$

$Z_{i, t}=\Lambda_{i} Z_{i, t-1}+A_{i, 0}^{-1} \varepsilon_{i, t}$, where $\Lambda=\left[\begin{array}{cccc}A_{i, 0}^{-1} A_{i, 1} & A_{i, 0}^{-1} A_{i, 2} & \ldots & A_{i, 0}^{-1} A_{i, p} \\ I & 0 & \ldots & 0 \\ 0 & I & \ldots & 0 \\ \vdots & \vdots & \ddots & \vdots \\ 0 & \ldots & I & 0\end{array}\right]$ 
The impulse response for variable $k$ to a U. S. monetary policy shock at horizon $h=1, \ldots, H$ is denoted by:

$$
\operatorname{IRF}_{k}(1, h)=\Lambda_{i}^{h-1} A_{i, 0}^{-1}(k, 1)
$$

That is, the impulse response of the variable k to U. S. monetary policy shock will be in the $k^{\text {th }}$ row and first column, for $h=1, \ldots, H^{8}{ }^{8}$

Each equation of the system is estimated using ordinary least squares (OLS), with 2 lags following the Schwartz Criterion. Statistical inference is based on Runkle's (1987) bootstrapping method to adjust for the fact that the data is in a panel format. This procedure consists of the following steps:

1. Estimate the PVAR(p) in equation (2) and generate 500 bootstrap replications of the coefficient matrix $\hat{A}_{i} \cdot$ ?

2. IRFs are computed 500 times for each generated variable $k^{*}$ to the first structural shock (that is the U. S. monetary policy shock) at horizon $h=1, \ldots, H$.

3. Finally, the bootstrap simulations are used to calculate the empirical distribution for the IRFs. One standard deviation confidence intervals are constructed from the simulated estimates using the structural errors and without imposing symmetry in the confidence bands.

\section{Results}

Figure 3 shows the impulse responses to a one percentage point reduction in the U. S. monetary policy rate obtained from estimating the PVAR using a sample of 25 EMDEs from 2000-17. Solid lines represent the OLS point estimates while dotted gray lines are one standard deviation confidence bands constructed using the empirical distribution obtained from the bootstrap procedure. Reflecting the unprecedented scale of monetary policy support in the United States following the global financial crisis, there is a protracted decline the U.S. shadow policy rate following the initial, reaching a cumulative decline of 1.6 percentage points in the five year horizon window (Figure 3, panel 1). Consistent with the empirical evidence on the behavior of EMDEs' currencies in the last two decades, the real effective exchange rate appreciated on the year of the U. S. monetary policy shock, but this appreciation is not statistically significant and reverted after the second year (Figure 3, panel 2).

\footnotetext{
${ }^{8}$ This representation also requires augmenting both the $A_{i, 0}^{-1}$ and $\varepsilon_{i, t}$ with $(k+1) \times p$ rows or columns of zeros for the matrix multiplication to work, given the dimension of $Z_{i, t}$, which is $(p+1) \times(k+1)$.

${ }^{9}$ Bootstrapping for the panel was done by generating initial conditions separately for each country as in Runkle (1987), but sampling from the entire panel vector of residuals. This was done to account for possible crosscountry correlations.
} 
The strengthening of the currency, summarized in the REER response, coincided with a reallocation of resources across sectors in these economies. Figure 3 (panel 3) shows the response of the share of manufacturing value added in GDP. The U. S. monetary policy shock and the ensuing currency appreciation in EMDEs coincides with a contraction in the share of manufacturing production. The contraction of tradable output is also relatively long-lasting throughout the IRF 5 year horizon. This result is consistent with the findings of Rajan and Subramanian (2011), who document that in episodes of surges of foreign capital (in the form of aid) to EMDEs, exportable industries grow slower by about half percentage point per year relative to non-exportable industries. All in all, these results suggest that Dutch disease effects were common among EMDEs as a results of large shifts in global financial conditions.

Figure 3. Effects of U. S. monetary policy Shocks on EMDEs

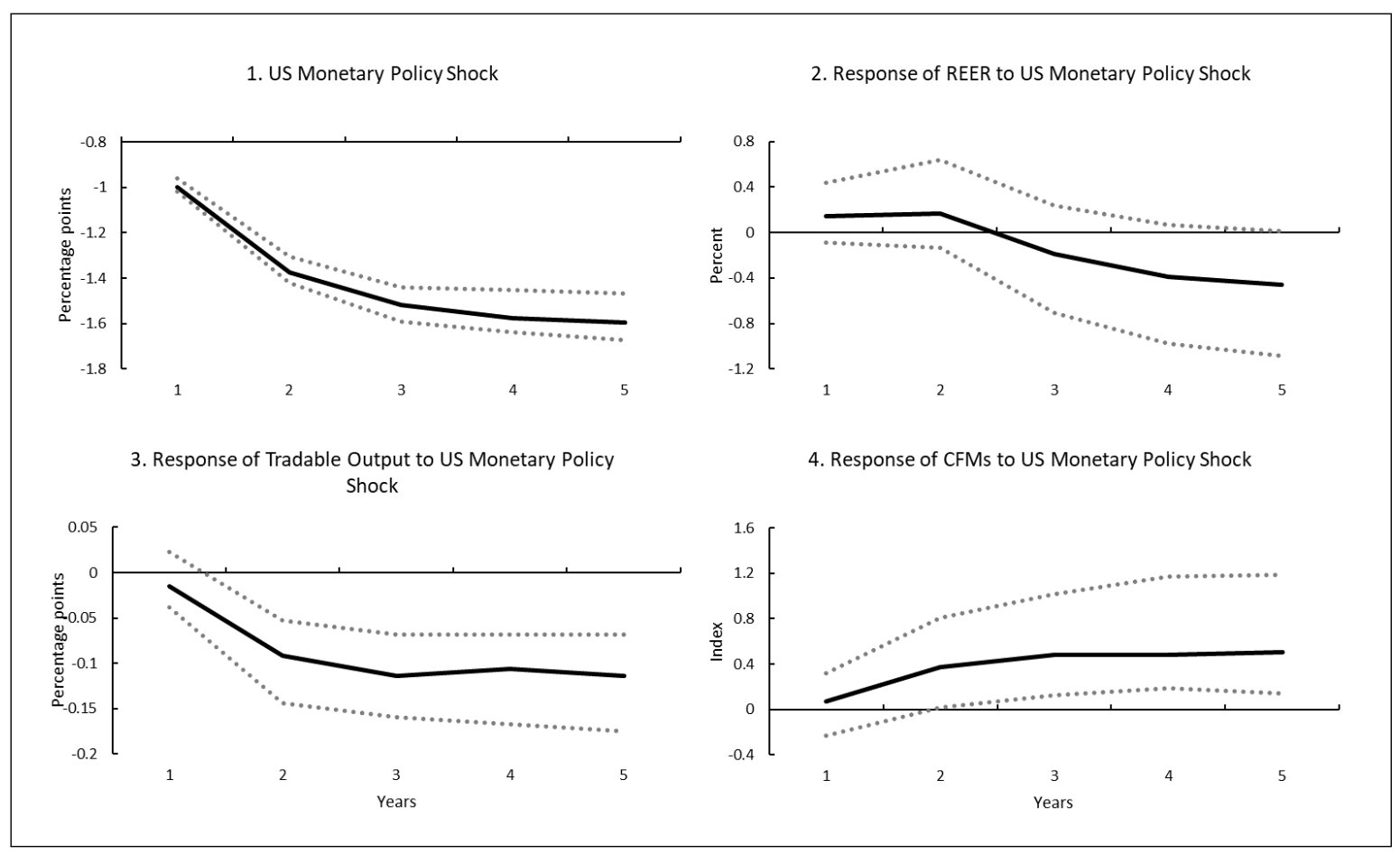

Note: Solid black lines represents OLS point estimate. Dashed lines are one standard deviation confidence bands.

In terms of policy response, following the U. S. monetary policy shocks, it was also common to see a tightening of CFMs on inflows in the sample of 25 EMDEs (Figure 3, panel 4). Given the construction of the CFM index, it is not possible to identify this reaction as an increase in the intensity of CFMs, instead what the IRF shows is the introduction of new restrictions in the capital account. In this regard, the result can be interpreted as EMDEs increasing restrictions on one additional asset category in the year after the U. S. monetary policy shock.

Robustness and extensions. In order to assess the robustness of these results and to get a better sense of the results presented above, this paper looks into whether the presence of 
Dutch disease effects and the use of CFMs was more common in $(i)$ the post-GFC period; (ii) in EMDEs with a more flexible exchange rate regime; (iii) and in EMDEs compared to small and open advanced economies (AEs). These extensions are going to be incorporated to the baseline analysis described by allowing the coefficients in the $A_{i, j}$ matrix described in equation (2) to vary depending on conditions $(i)$ to $(i i i):{ }^{10}$

$$
A_{i, j}=\beta_{i, j}+\varsigma_{i, j} * \text { Conditions }_{i, t}
$$

As shown in Figure 1, there was a structural change in the magnitude of capital inflows going to EMDEs in the post GFC period explained mainly by unprecedented U. S. monetary policy stimulus. In this regard, it could be expected that an expansionary monetary policy shock would be more relevant for the post-GFC period and that Dutch disease effects and use of CFMs to be more prevalent among EMDEs. To confirm this hypothesis, the PVAR coefficients are interacted (as described in equation 4) with a post-GFC dummy variable, that equals one from 2009 until 2017 and zero otherwise.

Figure 4. Effects of U. S. monetary policy Shocks on EMDEs, Pre- and Post-GFC

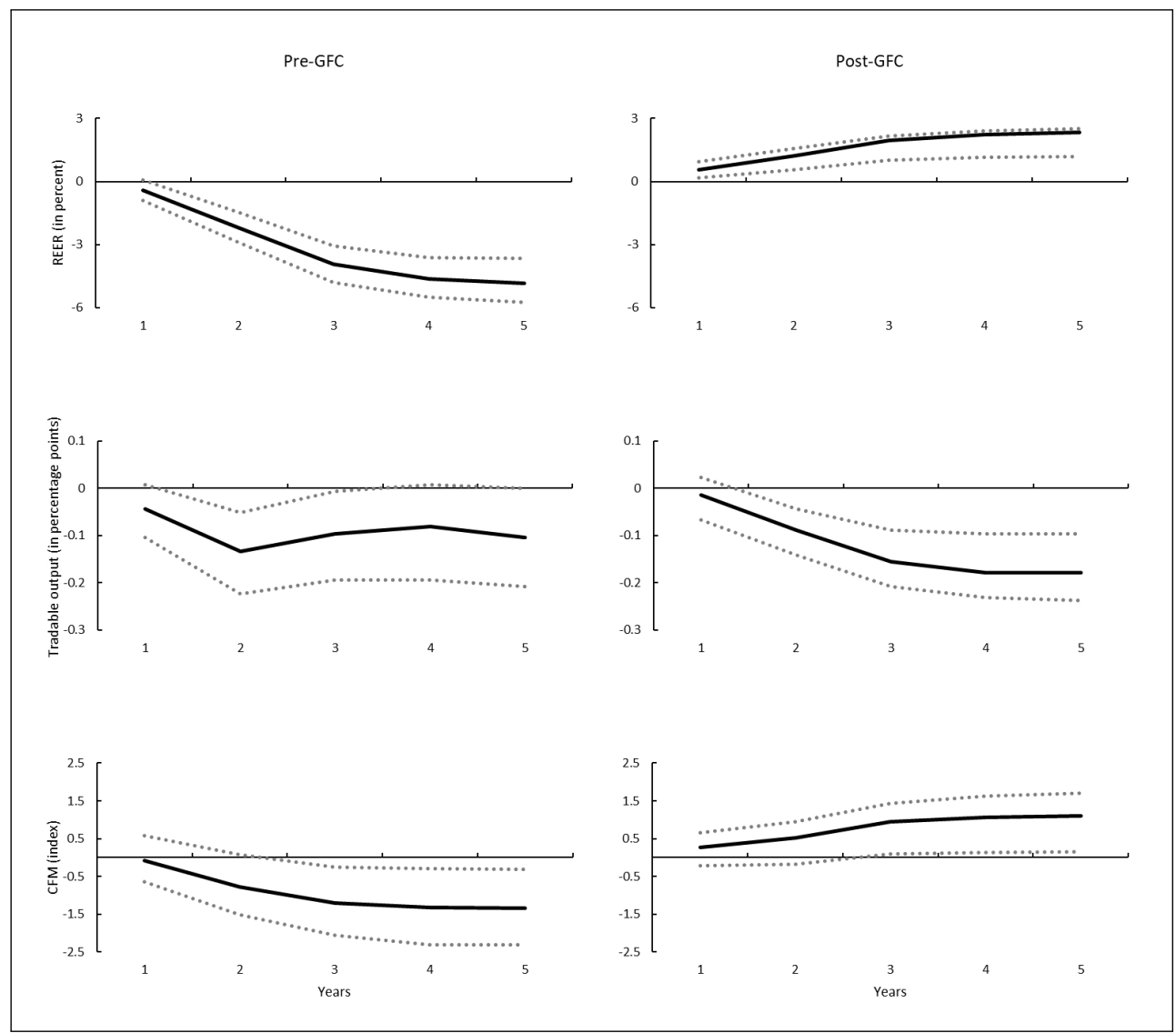

Note: Solid black lines represents OLS point estimate. Dashed lines are one standard deviation confidence bands.

${ }^{10}$ see Towbin and Weber, 2013 for a discussion of PVARs with interaction terms 
The results presented in Figure 4 confirm that Dutch disease effects and the use of CFMs were common in EMDEs as a result of U. S. monetary policy shocks in the aftermath of the GFC. Before the GFC, expansionary U. S. monetary policy shocks led to weaker currencies, and the effect of the shock on tradable output was somewhat limited (left panels). Many of these economies also reduced the number of CFM restrictions following the U.S. shock. On the other hand, looser U. S. monetary policy after the GFC resulted in significant currency appreciation, with the effect of U.S. shocks having a protracted effect on the REER (right panels). These changes in relative prices led to a significant reduction in tradable output, confirming the presence of Dutch disease. As in the baseline case, EMDEs typically responded to these events by imposing additional restrictions on the capital account. ${ }^{11}$

Figure 5. Effects of U. S. monetary policy Shocks on EMDEs, by Exchange Rate Regime

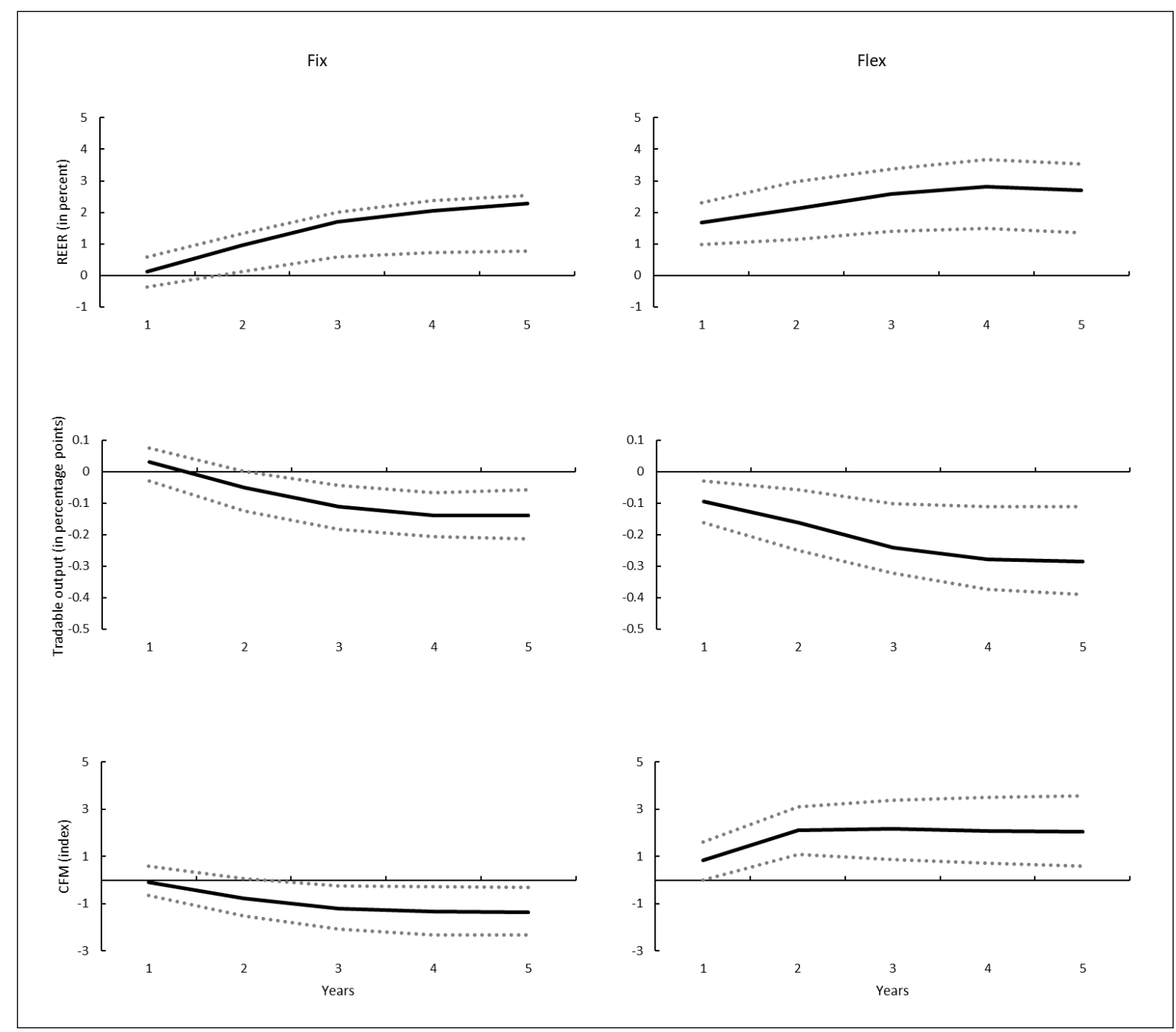

Note: Solid black lines represents OLS point estimate. Dashed lines are one standard deviation confidence bands.

${ }^{11}$ These results are in line with Kolasa and Wesolowski (2020), which finds that unconventional monetary policy in the United States led to negative output spillovers in emerging markets. 
The different reactions pre- and post-GFC may not be the result of differences in the effects of U.S. monetary policy, but instead of changes in exchange rate policies in EMDEs. Recent empirical work has documented that movements in currencies following external shocks depend on the degree of exchange rate flexibility (see Carrière-Swallow, Magud, and Yépez, 2021). At the same time, economies under a fixed exchange rate regime are likely to already have extensive currency controls, hence the scope to add an additional restriction is more limited. In order to test these hypothesis, the baseline analysis is also extended to assess whether the occurrence of Dutch disease and the use of CFMs depends on the degree of exchange rate flexibility. To do this, the analysis augments the baseline specification in equation (2) by including interaction terms (as shown in equation 4) with a dummy equal to one if the EMDE has a peg ("fix") and zero for non-peg ("flex"). The exchange rate classification is from Ilzetzki and others (2017).

The results presented in Figure 5 confirm that indeed Dutch disease effects were more common among EMDEs with a more flexible exchange rate regime, with these economies resorting to the use of CFMs on inflows (right panels). ${ }^{12}$ Following an expansionary U. S. monetary policy shock, currencies appreciated and the share of manufacturing value added in GDP declined in significantly larger magnitudes in EMDEs with more flexible exchange rate regimes. In these economies the larger presence of Dutch disease coincided also with the imposition of additional restrictions on capital inflows.

The paper also look at whether U. S. monetary policy shocks also gave rise to Dutch disease effects and/or the use of CFMs in AEs. A number of papers have documented that global financial conditions appear to drive capital flows to EMDEs even more so than for AEs (see for example, Forbes and Warnock, 2012; Fratzscher, 2012). Given the larger presence of currency mismatches and lower policy credibility, policies aimed at stabilizing the exchange rate are more likely to be deployed in EMDEs than in AEs (see Rogoff and others, 2014). In this regard it could be expected that the use of CFMs to be more common in EMDEs than in AEs.

To shed light on the differences between EMDEs and AEs, the sample is expanded to include eight small open AEs. The selection criteria for AEs was similar to the baseline sample, mainly that there was at least one change in the annual CFM index during the period of analysis and that the economies do not form part of a currency union (as it is not possible to consider these economies as independent cross-sectional observations). ${ }^{13}$ Impulse responses are constructed by augmenting equation 2 to include an interaction (as shown in equation 4) between the PVAR coefficients a dummy variable that equal one if a country is an EMDE and zero if AE.

The results suggest that Dutch disease following U. S. monetary policy shocks occurred mainly in EMDEs (Figure 6). For AEs (left panel), the currency depreciates following the

\footnotetext{
${ }^{12}$ The analysis uses the whole sample, conditioning the PVAR coefficients on the degree of exchange rate flexibility as explained in equation 4.

${ }^{13}$ The AEs included are: Canada, Czech Republic, Iceland, Israel, Korea, Norway, Singapore, and Sweden.
} 
shock, albeit not in a statistically significant way. The weaker currency helped to stimulate tradable output, with the share of manufacturing value added in GDP increasing somewhat at the end of the IRF horizon. Interestingly, AEs also made use of CFMs.

Figure 6. Effects of U. S. monetary policy Shocks on EMDEs, by Income Group

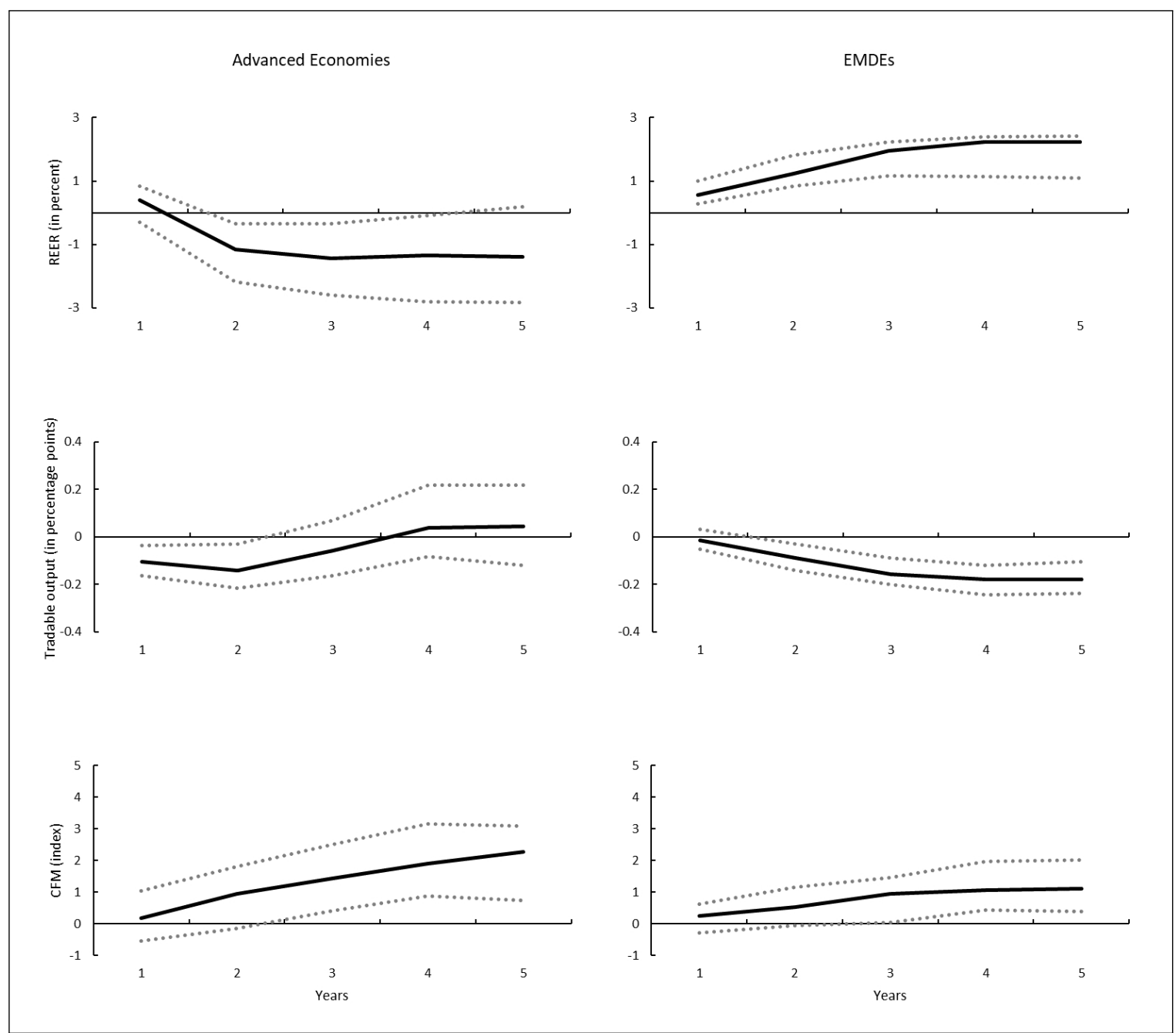

Note: Solid black lines represents OLS point estimate. Dashed lines are one standard deviation confidence bands. 
Figure 7. Effects of U. S. monetary policy Surprises on EMDEs

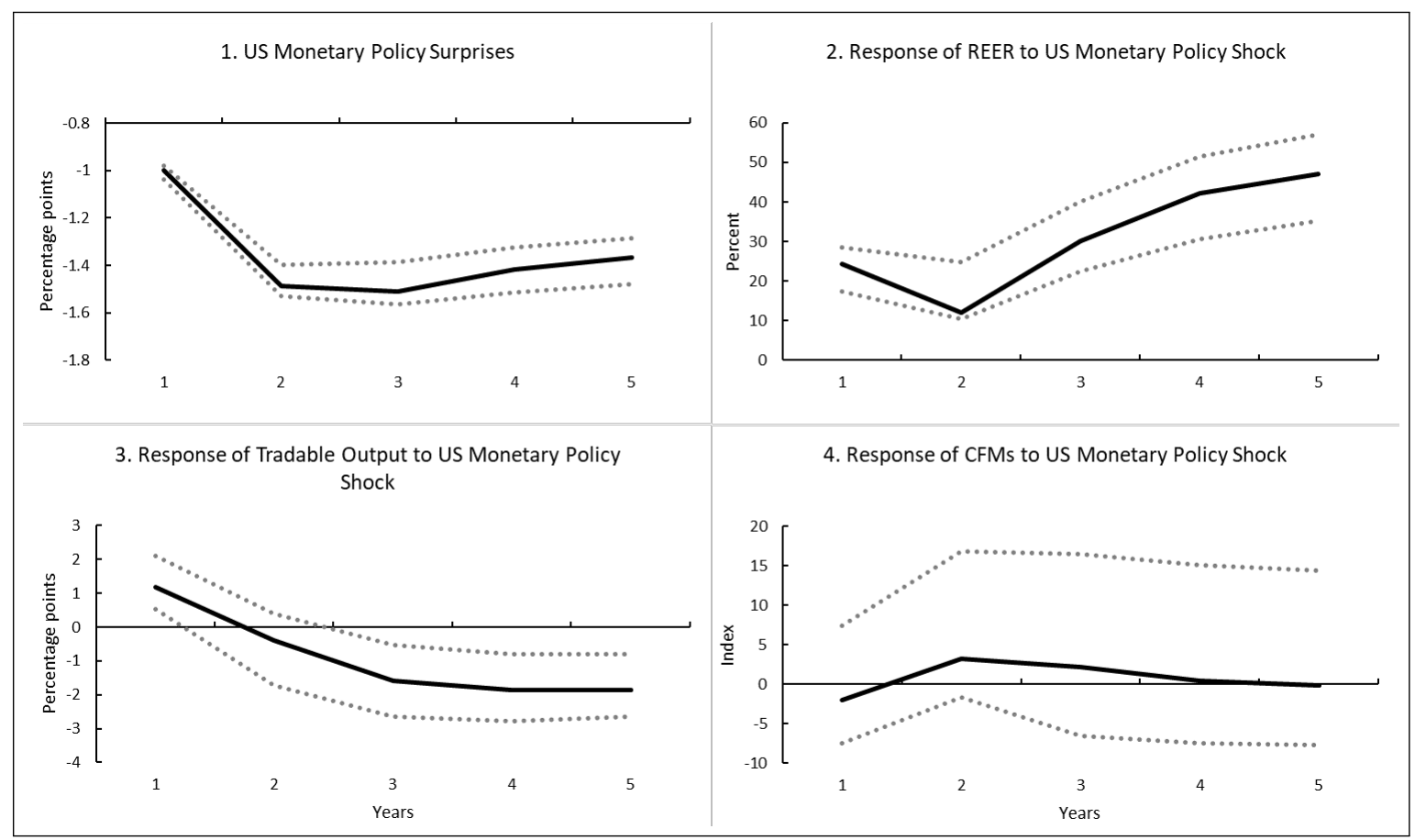

Note: Solid black lines represents OLS point estimate. Dashed lines are one standard deviation confidence bands.

As a final extension to the empirical analysis, the paper looks at whether Dutch disease effects in EMDEs are also evident when using a different measure of U. S. monetary policy shocks. Jarociński and Karadi (2020) use unexpected changes in federal funds rate and Eurodollar futures on Federal Open Market Committee (FOMC) dates to measure policy surprises. Using a high frequency identification strategy, they can rule out the simultaneity of economic news and monetary policy. In this paper, the U. S. monetary policy surprises are accumulated within a year and used to estimate causal effects running from U. S. monetary policy shocks to the REER, tradable output, and CFMs in EMDEs.

Dutch disease effects in EMDEs are also evident following expansionary U. S. monetary policy surprises (Figure 7). An unanticipated loosening in U. S. monetary policy leads to a multilateral real appreciation of currencies on the year after the shock, and a subsequent protracted contraction in the share of manufacturing in GDP. As in the baseline, EMDEs respond by tightening CFMs, although the IRF is somewhat noisier and less precise.

Given these results, a natural question is to ask whether the use of CFMs helps EMDEs in attenuating Dutch disease effects. Equation 1 helps to illustrate how one could conceptually analyze how U. S. monetary policy shocks affect the REER (i.e., the transmission mechanism). There is a contemporaneous effect through coefficient $a_{i, 3,1}$ and dynamically through the relevant coefficients in the $A_{i, j}$ matrices. But there are also indirect effects of U. S. monetary policy shocks to the extent that these shocks lead to more CFMs contemporaneously (through $a_{i, 2,1}$ ) and in turn CFMs impact the REER (through $a_{i, 3,2}$ ). Moreover, CFMs can 
insulate EMDEs from U. S. monetary policy shocks if they respond to these shocks at any horizon and the coefficients for lagged values of CFMs in the REER and output equations are significant.

However, the coefficients in the PVAR are not "deep" parameters, as these are not based on micro-foundations, which limits the use of the PVAR to perform a counterfactual analysis of what would have happened if there was no CFM response (i.e., the coefficients for the CFM variable are set to zero in equation 1). As explained in Lucas (1976), there is the possibility that if the process followed by the policy of implementing CFMs differed from the historical pattern, other equations of the system might have behaved differently as well. Therefore, a structural model, with micro-founded parameters, is needed in order to evaluate the appropriateness of CFMs in limiting Dutch disease. The paper develops this model in the next section.

\section{THE THEORETICAL MODEL}

A dynamic stochastic general equilibrium (DSGE) model is developed in order to qualitatively match the empirical findings presented in the previous section. The model is similar to Arellano (2009). It uses a small open economy assumption and consists of a representative household and two industries (tradable and non-tradable). Households have restricted access to international credit markets, as there is a tax on foreign debt (i.e., a CFM).

In order to justify the use of CFMs, the model includes an externality in the production technology of tradable goods. The externality is a learning-by-doing (LBD) mechanism and is incorporated along the lines of Cooper and Johri (2002). Firms in the tradable sector do not take into account the LBD process in their production process. Since the planner solution internalizes this process in the production of tradables, this sector will face increasing returns to scale on the aggregate level, while constant returns to scale technology at the firm level as in Romer (1986). This externality produces an inefficient allocation of resources following a shock to the global interest rate.

\section{A. Households}

Households in the economy maximize their expected lifetime utility and have preferences over consumption and leisure:

$$
U=E_{0} \sum_{t=0}^{\infty} \beta^{t} \frac{\left(c_{t}^{\omega}\left(1-h_{t}\right)^{1-\omega}\right)^{1-\gamma}-1}{1-\gamma} .
$$

$\beta$ is a subjective discount factor. Household consumption, $c_{t}$, consists of non-tradable consumption $c_{N, t}$, and tradable consumption, $c_{T, t}$, and has a constant elasticity of substitution 
form:

$$
c_{t}=\left[\varphi\left(c_{T, t}\right)^{-\mu}+(1-\varphi)\left(c_{N, t}\right)^{-\mu}\right]^{-\frac{1}{\mu}} .
$$

Labor, $h_{t}$, is allowed to move freely between the two sectors $\left(h_{t}=h_{T}+h_{N}\right)$, making the wage households receive the same in both sectors.

The flow budget constraint, in tradable good terms, is as follows:

$$
B_{t}=\left(1+r_{t-1}^{d}\right) B_{t-1}-w_{t} h_{t}-r_{t}^{k} k_{t}-T_{t}-\Pi_{t}^{f}+p_{N, t} c_{N, t}+c_{T, t}+i_{t}+\frac{\kappa}{2}\left(B_{t}-\bar{B}\right)^{2} .
$$

$B_{t}$ denotes the household's foreign debt position, $p_{N, t}$ is the relative price of non-tradables in terms of tradables (equivalent to the real exchange rate ), $k_{t}$ is capital, $i_{t}$ is investment. ${ }^{14}$

$\frac{\kappa}{2}\left(B_{t}-\bar{B}\right)^{2}$ is the cost of adjusting the country's foreign debt position. Following SchmittGrohé and Uribe (2003), the model introduces these adjustment costs with the sole purpose of eliminating the familiar unit root built in the dynamics of standard formulations of the small open economy model. As discussed in Uribe and Yue (2006), the debt adjustment cost can be decentralized as a bank operational cost.

$T_{t}$ denotes government lump sum transfers, and $\Pi_{t}^{f}$ are dividends received from firms. The interest rate at which the households can borrow from international markets is given by:

$$
r_{t}^{d}=\left(1+\tau\left(B_{t}\right)\right) \exp \left(-\eta_{t}\right) r^{*}
$$

$\tau\left(B_{t}\right)$ denotes taxes on foreign debt interest rate payments and have the following functional form (as in Kitano, 2011):

$$
\tau\left(B_{t}\right)=\frac{\tau}{2}\left(B_{t}-\bar{B}\right)^{2}
$$

where $\tau$ is a parameter representing the intensity of the tax, and $\bar{B}$ denotes the economy's steady state foreign debt position. ${ }^{15}$ Foreign debt interest rate payments are based on the world interest rate $r^{*}$, which is exogenously determined, and subject to a random disturbance term denoted by $\eta_{t}$. Finally, $r_{t}^{k}$ is the rental rate of capital and $w_{t}$ is the real wage. The process of capital accumulation is given by:

$$
k_{t+1}=(1-\delta) k_{t}+i_{t}-\frac{\phi}{2}\left(\frac{k_{t+1}-k_{t}}{k_{t}}\right)^{2}
$$

where $\frac{\phi}{2}\left(\frac{k_{t+1}-k_{t}}{k_{t}}\right)^{2}$ represents a capital adjustment cost.

\footnotetext{
${ }^{14}$ Investment is in tradables only.

${ }^{15} \bar{B}$ is calibrated to equal to 0 in steady state, thus tax revenues are on the full stock of foreign debt.
} 
Optimality conditions for consumption, labor, foreign debt, and capital are:

$$
\begin{gathered}
\frac{1-\varphi}{\varphi}\left(\frac{c_{N, t}}{c_{T, t}}\right)^{-(\mu+1)}=p_{N, t}, \\
\frac{\omega}{1-\omega} \frac{1-h_{t}}{c_{t}}=\frac{p_{N, t}}{w_{t}} \\
-\lambda_{t}\left(1-\kappa\left(\frac{B_{t}-\bar{B}}{\bar{B}}\right)\right)+\beta^{t}\left(1+\exp \left(-\eta_{t}\right) r^{*}\left(1+\tau\left(B_{t}\right)+\tau^{\prime}\left(B_{t}\right) B_{t}\right)\right) E_{t}\left[\lambda_{t+1}\right]=0,
\end{gathered}
$$

and

$$
-\lambda_{t}\left[1+\phi\left(k_{t+1}-k_{t}\right)\right]+\beta^{t} E_{t}\left[\lambda_{t+1}\left(1+r_{t+1}^{k}-\delta+\phi\left(k_{t+2}-k_{t+1}\right)\right)\right]=0 .
$$

The marginal utility of consumption is denoted by:

$$
\lambda_{t}=\omega c_{t}^{\omega(1-\gamma)-1}\left(1-h_{t}\right)^{(1-\omega)(1-\gamma)} .
$$

\section{B. Firms}

There are two sectors in this economy: tradable and non-tradable. Firms in both sectors are competitive. Following the Dutch disease literature (see Lama and Medina 2012 and the discussion therein), the production of tradables in this economy is subject to an LBD externality. Firms in this sector choose labor and capital to maximize profits, and produce output according to a Cobb-Douglas production function:

$$
Y_{T, t}=A_{T, t} l_{t}^{\xi} k_{t}^{\alpha} h_{T, t}^{1-\alpha}
$$

$A_{T, t}, k_{t}$, and $h_{T, t}$ denote an exogenous productivity shock, capital, and labor, respectively with both $\alpha$ and $\xi$ between zero and one. Average organizational capital in the production of tradables is denotes by $l_{t}$, and is specified as in Cooper and Johri (2002):

$$
l_{t+1}=l_{t}^{\zeta} Y_{T, t}^{\psi},
$$

with $\zeta+\psi=1$. The rationale behind this LBD mechanism is that production in the tradable sector increases the experience of workers, and this further improves productivity in the future. As in Romer (1986), individual firms assume that they cannot affect the aggregate stock of organizational capital, so they take $l_{t}$ as given. This makes firms infer that they are facing a constant returns to scale technology, making the problem of the firm quite standard. 
On the other hand, a social planner would observe that (12) is an increasing return to scale technology at the aggregate level, therefore considering the effect of the LBD mechanism in production via the experience gained. This externality can be viewed as a moving cost from the tradable to the non-tradable sector, and if this cost is not internalized by firms, it will have considerable implications for the economy's aggregate welfare levels.

Firms in the non-tradable sector produce output with a simple technology that is linear in labor and is described by:

$$
Y_{N, t}=A_{N, t} h_{N, t}
$$

where $A_{N, t}$ is a sector specific exogenous productivity shock . Labor is perfectly mobile across sectors. Firms in the two sectors obtain their inputs for production from the household, so that in equilibrium the wage rate equals the marginal productivity of labor and the rate of return on capital equals the marginal productivity of capital. Since in equilibrium marginal productivity of labor across sectors are equalized, leading to

$$
w_{t}=(1-\alpha) \frac{Y_{T, t}}{h_{T, t}}=p_{N, t} \frac{Y_{N, t}}{h_{N, t}} .
$$

Finally, the optimality condition for capital is

$$
r_{t}^{k}=\alpha \frac{Y_{T, t}}{k_{T, t}}
$$

\section{Government}

For simplicity, it is assumed that the government runs a balanced budget. Its revenue, the CFM tax, is rebated back to households as lump sum transfers,

$$
T_{t}=\tau\left(B_{t}\right) \exp \left(-\eta_{t}\right) r^{*} B_{t}
$$

\section{Equilibrium}

The market clearing conditions for labor and the two production sectors are:

$$
\begin{gathered}
h_{t}=h_{T, t}+h_{N, t} . \\
Y_{N, t}=c_{N, t} . \\
Y_{T, t}=c_{T, t}+i_{t} .
\end{gathered}
$$


The competitive equilibrium of this model is defined as the state contingent sequences of allocations and prices

$$
\left\{c_{N, t}, c_{T, t}, k_{t+1}, h_{t}, h_{N, t}, h_{T, t}, p_{N, t}, B_{t}, r_{t}^{k}, w_{t}\right\}_{t=0}^{\infty}
$$

such that 1) households maximize expected utility subject to their budget and time constraints taking prices as given, 2) firms maximize profits subject to their technology taking input prices as given, and 3) markets clear.

\section{E. Parameterization}

The parameters used to solve and simulate the model are listed in Table (1). The time frequency is supposed to be quarterly. All of the parameters with the exception of tradable production technology are obtained from similar studies of small open economies and are typical parameters used in the real business cycle literature. The parameters for the tradable production are obtained from Cooper and Johri (2002), which estimate parameters for equations (12) and (13) simultaneously using 2-digit manufacturing data for the US. In order to fully identify the parameters of the system, some restrictions have to be imposed. For the purpose of this paper, the parameters used correspond Cooper and Johri (2002) estimation assuming increasing returns to scale in the production function. ${ }^{16}$

The parameter for the foreign debt adjustment cost is the smallest possible value close to zero, so that any effect on domestic interest rates is primarily driven by debt levels and capital controls. ${ }^{17}$ The model is solved numerically by taking log-linear approximations of the equilibrium conditions around the steady state.

This chapter assumes that the processes for the shocks affecting the economy are:

$$
\begin{gathered}
\ln \left(A_{T, t}\right)=0.95 \ln \left(A_{T, t-1}\right)+\varepsilon_{T, t}, \varepsilon_{T, t} \sim N\left(0, \sigma_{T}^{2}\right), \sigma_{T}=0.007 \\
\ln \left(A_{N, t}\right)=0.95 \ln \left(A_{N, t-1}\right)+\varepsilon_{N, t}, \varepsilon_{N, t} \sim N\left(0, \sigma_{N}^{2}\right), \sigma_{N}=0.0035
\end{gathered}
$$

and

$$
\eta_{t}=0.98 \eta_{t-1}+\varepsilon_{\eta, t}, \varepsilon_{\eta, t} \sim N\left(0, \sigma_{\eta}^{2}\right), \sigma_{\eta}=0.01
$$

The persistence parameters and the standard deviations for the technology in both sectors are obtained from Lartey (2008). Given the quarterly frequency of the model, the parameters for the foreign interest rate are estimated using the U.S. three-month treasury bill rate.

\footnotetext{
${ }^{16}$ It is worth noting that from all their identification methods, assuming increasing returns to scale is the only one that produces all estimates of production parameters to be significantly different from zero.

${ }^{17}$ This parameter cannot be set equal to zero, since bond holding costs are necessary to ensure bond holdings do not display a unit root (Schmitt-Grohé and Uribe, 2003)
} 
Table 1. PARAMETERIZATION

\begin{tabular}{lcll}
\hline \hline Parameter & Symbol & Value & Source \\
\hline Foreign interest rate & $r^{*}$ & 0.02 & Standard \\
Share of tradables in consumption & $\varphi$ & 0.45 & Uribe and Yue (2006) \\
Subjective Discount Factor & $\beta$ & 0.98 & \\
Inv. elast. of intertemp. sub. & $\gamma$ & 2 & Acosta and others (2009) \\
Elast. of sub., consumption & $\omega$ & 0.22 & Acosta and others (2009) \\
Elast. of sub., tradables & $\mu$ & 0.316 & Acosta and others (2009) \\
Foreign debt adjustment cost & $\kappa$ & 0.0003 & Author \\
Parameter for investment adj. cost & $\phi$ & 2.2 & Acosta and others (2009) \\
Capital share & $\alpha$ & 0.33 & Cooper and Johri (2002) \\
Labor share, tradable sector & $\Phi$ & 0.67 & Cooper and Johri (2002) \\
Learning rate & $\xi$ & 0.26 & Cooper and Johri (2002) \\
Output elasticity, org. capital & $\psi$ & 0.5 & Cooper and Johri (2002) \\
Depreciation rate, org. capital & $\zeta$ & 0.5 & Cooper and Johri (2002) \\
Depreciation rate & $\delta$ & 0.025 & Lama and Medina (2012) \\
\hline
\end{tabular}

\section{F. Model simulations}

This subsection presents the impulse response functions (IRFs) from the model simulations to a two standard deviation reduction in the world interest rate. The IRFs show the effect one year (i.e., four quarters) after impact. In order to illustrate the endogenous effect of CFMs in insulating the economy from a global interest rate shock, simulations are run for different levels of the tax on foreign interest rate payments $(\tau)$.

Results show that a (negative) two standard deviation shock to the world interest rate increases net foreign borrowing (Figure 8, panel 1), which in turn leads to higher consumption of both tradables and non-tradables. The higher demand for non-tradables increases wages and the relative price of non-tradables (Figure 8, panel 2), causing labor to reallocate from the tradable to the non-tradable sector (Figure 8, panel 3). This reallocation of labor causes a contraction of output in the tradable sector (Figure 8, panel 4). All in all, the model does a good job of capturing Dutch disease effects in response to the increased availability of foreign financed tradable goods.

This theoretical simulation allows the analysis to isolate the role of CFMs. As shown in Figure 8 , by curving the availability of foreign capital, the tax on foreign debt payments (i.e., the CFM) limits the rise in relative prices (i.e. an appreciation of the currency) and the ensuing contraction in the tradable output. While it is clear from examining equation (12) that the initial contraction in the tradable sector will be exacerbated by a reduction in the level of organizational capital, it is not evident that limiting this contraction would be optimal from the social planner's point of view, as some reallocation from tradable to non-tradable sectors 
would still be an efficient response to an increase in the availability of foreign capital. The next subsection analyzes how the optimal CFM level that would allow for the most efficient reallocation or resources in the theoretical small open economy.

Figure 8. Theoretical Impulse Responses to Global Interest Rate Shocks

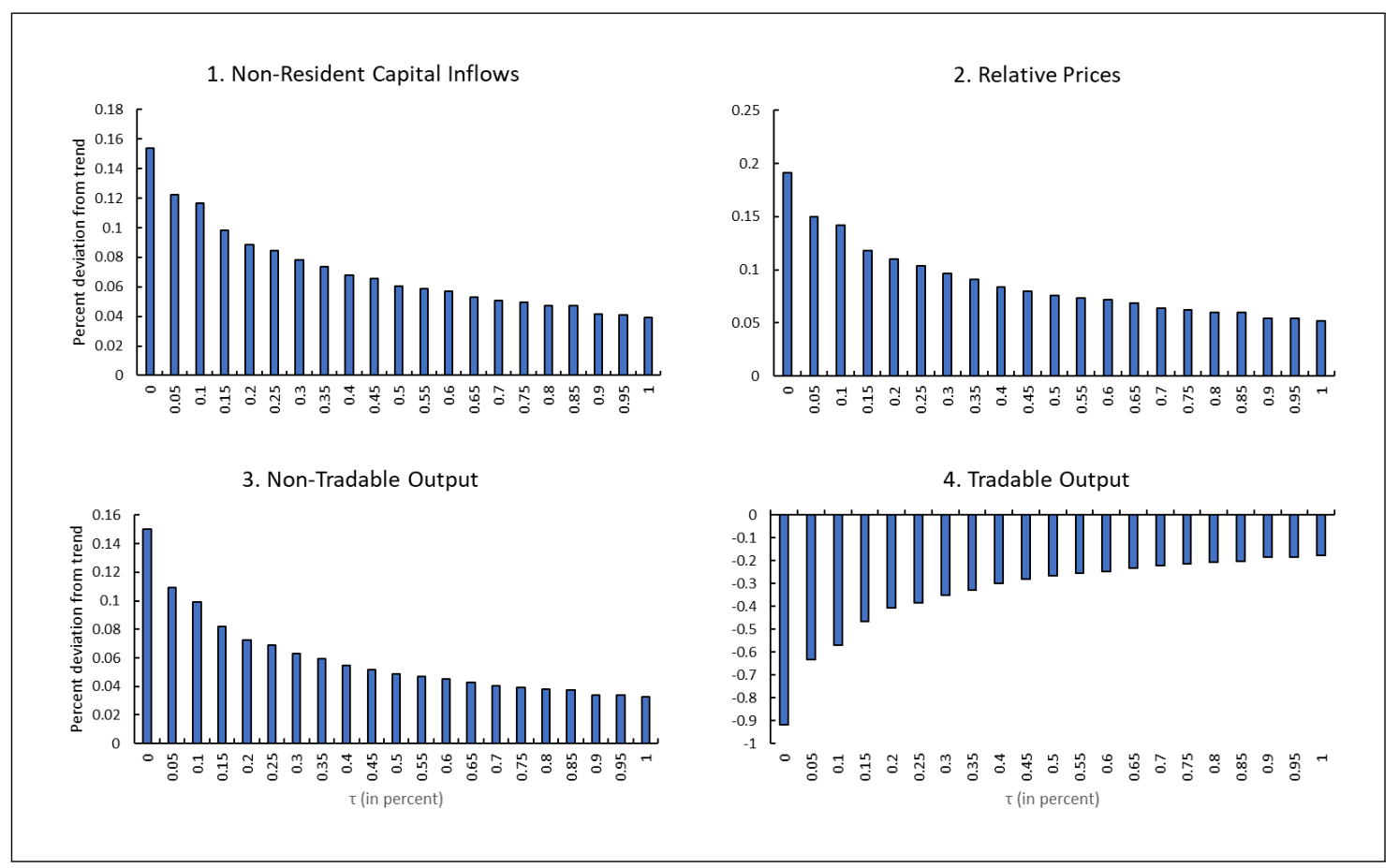

Note: Each bar corresponds to the one year response to a two standard deviation reduction in the global interest rate shock for different CFM $(\tau)$ rates.

\section{G. Welfare Analysis}

The welfare analysis is based on Schmitt-Grohé and Uribe (2004), and it calculates the fraction of consumption required for households in an economy with no CFMs to be as well off as households in an economy with CFMs. This welfare value is calculated for different CFM levels, represented by $\tau$ in the model, in order to identify the CFM rate that maximizes household's expected lifetime utility. The economy with no CFMs $(\tau=0)$ will be denoted by $\mathrm{B}$, and will be considered the benchmark model. On the other hand, the economy with CFMs $(\tau>0)$ will be denoted by $\mathrm{C}$. The conditional welfare function for each economy is represented by

$$
V_{0}^{B}=E_{0} \sum_{t=0}^{\infty} \beta^{t} U\left(c_{t}^{B}, h_{t}^{B}\right)
$$


and

$$
V_{0}^{C}=E_{0} \sum_{t=0}^{\infty} \beta^{t} U\left(c_{t}^{C}, h_{t}^{C}\right),
$$

where $c_{t}^{i}$ and $h_{t}^{i}$ represent the contingent plans for consumption and hours under economy $i$, with $i=B, C$. Let $\Psi^{l b d}$ denote the fraction of economy $C$ 's consumption required in order for households in economy $B$ to have the same welfare levels as households in economy $C$. Therefore, welfare is redefined as:

$$
V_{0}^{C}=E_{0} \sum_{t=0}^{\infty} \beta^{t} U\left(\left(1+\Psi^{l b d}\right) c_{t}^{B}, h_{t}^{B}\right) .
$$

Given the functional form of utility represented in equation (5), $\Psi^{l b d}$ can be written as

$$
\Psi^{l b d}=\left\{1-\left[\frac{(1-\gamma) V_{0}^{B}+\left(1-\theta_{t}\right)^{-1}}{(1-\gamma) V_{0}^{C}+\left(1-\theta_{t}\right)^{-1}}\right]^{\frac{1}{\omega(1-\gamma)}}\right\} .
$$

The welfare gain is computed through a second order approximation of equation (21). Figure 9 shows the welfare gain described in equation (21) under different values of $\tau$. Welfare is an increasing function in the level of CFMs up to $\tau=0.045$, meaning that 0.25 percent of household consumption should be transferred to a regime with no capital controls in order for households in that regime to have the same expected level of utility as households in a regime with capital controls in place.

As showed in the previous subsection, CFMs are effective in discouraging households from financing tradable consumption with foreign borrowing, therefore limiting costly resource reallocation from the tradable to the non-tradable sector, and thus increase agents' welfare. That is, when there is an LBD externality in this economy, restricting foreign borrowing can be considered close to a second-best policy. However, it is clear that the use of CFMs should be handled with care, as the benefits from CFMs dissipate relatively quickly, even for relatively low values of $\tau$. Results show that there are benefits from households having access to international capital markets, and some reallocation from the tradable to non-tradable sector is indeed the efficient response to capital inflow surges. All these issues highlight the implementation challenges of CFMs. 
Figure 9. Optimality of CFMs in an Economy with a Learning-by-Doing Externality

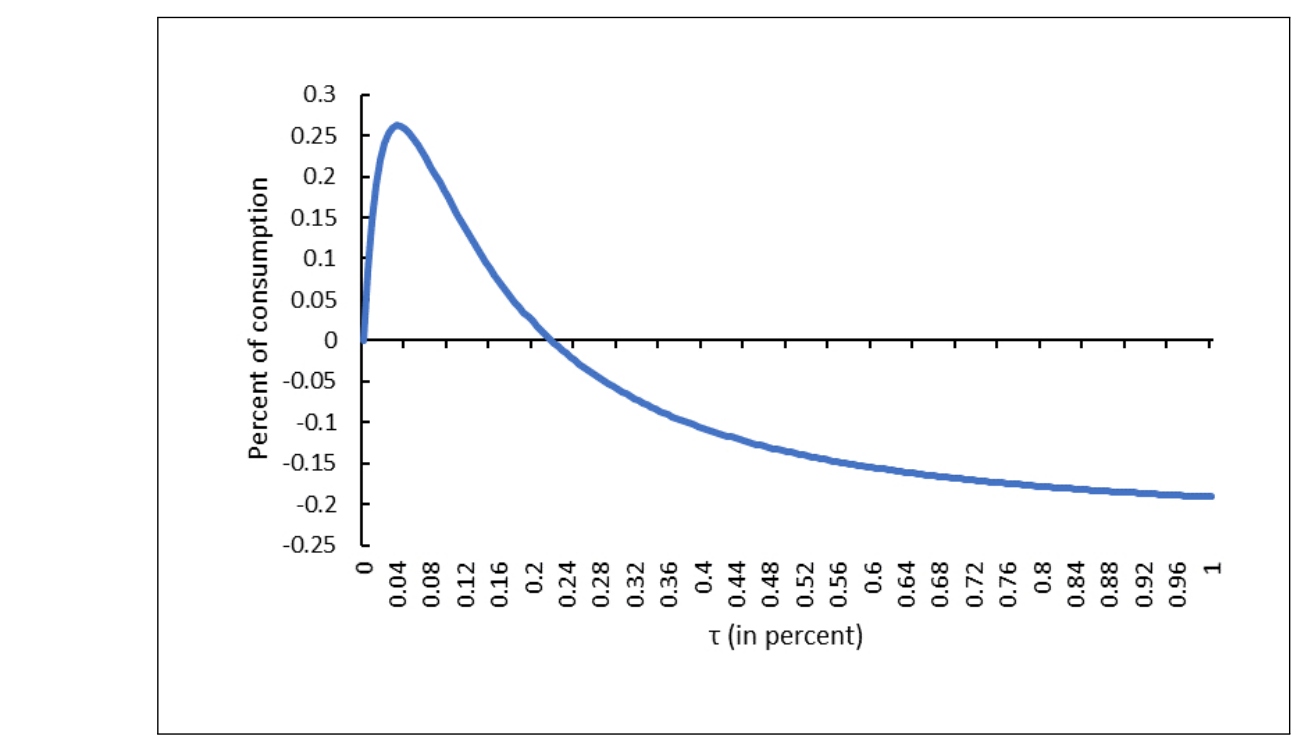

Note: This figure shows welfare gains from CFMs in terms of the fraction of consumption required for households under a regime with no CFMs to be as well off as households under a regime with CFMs. The horizontal axis measures the intensity of CFMS through the parameter $\tau$. The vertical axis measures the welfare benefit (in terms of consumption) of different degrees of CFMs.

\section{H. Sensitivity Analysis}

While most of the parameters used in this paper come directly from a large and standard strand of literature on small open economy models, they can be easily estimated from observable data. However, the parameters for the LBD mechanism are hard to estimate for EMDEs due to data constraints.

Against this backdrop, this subsection analyzes the sensitivity of the results to the share of organizational capital in the production function of tradables, the learning rate parameter $\xi$. This parameter is obtained from Cooper and Johri (2002), who estimates these parameters for U.S. manufacturing sector firms, and corresponds to the identification scheme of assuming that the production function exhibits constant returns to scale. As a robustness the importance of organizational capital in the tradable sector $(\xi)$ is reduced from 0.26 to 0.08 . This value is the lowest level of $\xi$ that allows the analysis to maintain the assumption regarding constant returns to scale of production at the firm level and increasing returns to scale at the aggregate level (i.e., $\alpha+(1-\alpha)+\xi>1)$.

Figure 10 shows the welfare benefit under the lower learning rate in the tradable sector (solid line). Even though the welfare benefit of CFMs is smaller as the benchmark specification, still the use of CFMs is welfare improving. A lower learning rate does not have a material effect on the model dynamics to global interest rate shocks. Nevertheless, the LBD mechanism is likely to be larger in EMDEs (as compared to the United States), as the share of manufactur- 
ing in the exportable sector is significantly larger in some of these economies. ${ }^{18}$ In this regard, the welfare gain from CFMs could be larger in some EMDEs, with the results presented in this paper representing a lower bound of the welfare benefit of CFMs in the presence of Dutch disease.

\section{Figure 10. Optimality of CFMs Under Different Levels of a Learning-by-Doing Externality}

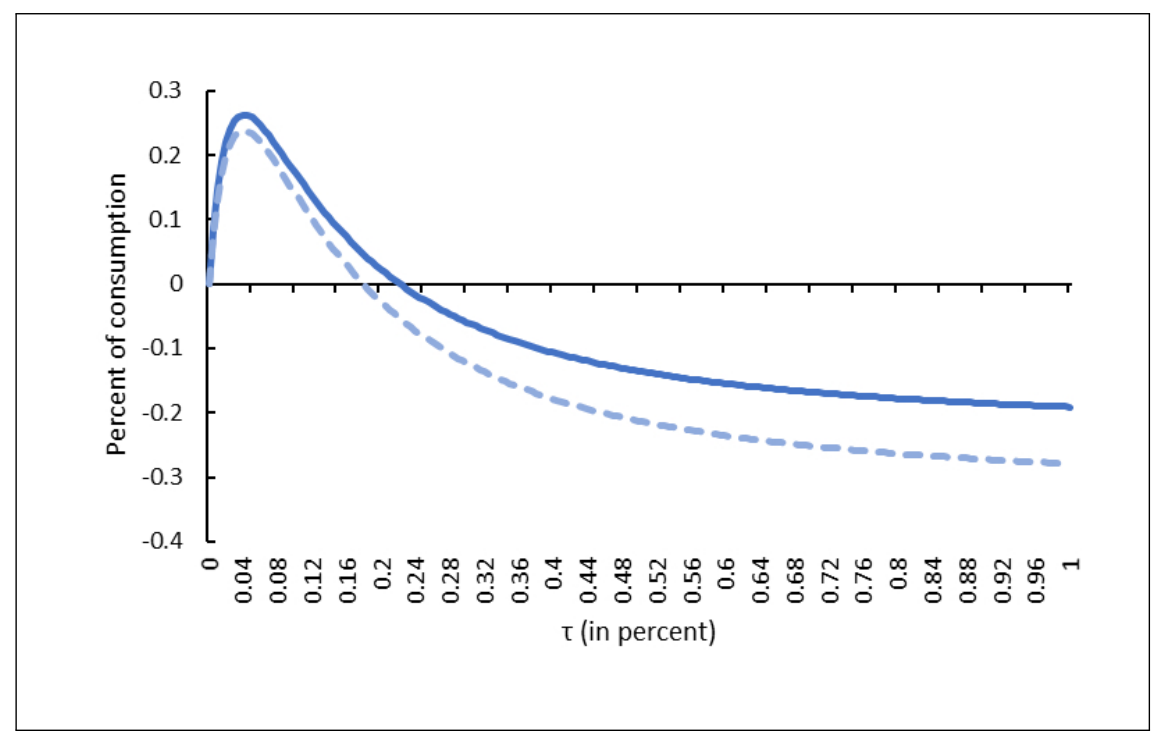

Note: This figure shows welfare gains from CFMs in terms of the fraction of consumption required for households under a regime with no CFMs to be as well off as households under a regime with CFMs. The horizontal axis measures the intensity of CFMs through the parameter $\tau$. The vertical axis measures the welfare benefit (in terms of consumption) of different degrees of CFMs. The solid line uses the baseline level of organizational capital $(0.26)$ and the dashed line uses a lower level of organizational capital (0.08).

\section{Conclusion}

This paper documented that accommodative monetary policy in the United States during the last decade and a half was followed by sharp increases of non-resident capital flows to EMDEs, which in turn gave rise to Dutch disease symptoms in these economies: real currency appreciation and a contraction in tradable output. The paper also shows evidence consistent with EMDEs using CFMs on inflows in response to U. S. monetary policy shocks. In order to evaluate the welfare implications of this policy intervention, the paper develops a DSGE small open economy model that exhibits an LBD externality in the tradable sector. The LBD externality calls for the use of CFMs on inflows to limit costly resource misallocation and to bring tradable production close to the efficient level. In this regard the use of CFMs to address Dutch disease effects would be most suitable for EMDEs with a sizable manufac-

\footnotetext{
${ }^{18}$ For example García-Cicco and Kawamura (2015), in a model calibrated to Chilean data, show that the level of organizational capital is much larger than the levels estimated by Cooper and Johri (2002) and commonly used in the literature.
} 
turing export sector, a sector identified in the literature as the one in which LBD accrues the most.

Using parameters commonly used in the Dutch disease literature, the paper finds that the use of CFMs could be a second-best policy if agents fail to internalize the moving cost of shifting resources from the tradable to non-tradable sectors in periods of higher foreign capital availability. However, model simulations suggest that the use of CFMs should be handled with care, as capital inflows do lead to some resource allocation efficiency gains and the benefits of CFMs accrue mainly at relatively low levels of restrictions. Also, the fact that the LBD externality is not observable and difficult to measure, calibrating CFMs (not only regarding their magnitude but also their duration) could be a challenging endeavor for policymakers. Importantly, the use of CFMs should not be a substitute for necessary macro adjustment to correct underlying imbalances, although CFMs appear as a sensible policy alternative that can provide policymakers some breathing space.

This paper puts forward an analytical framework with a novel mechanism to think about the merits of CFMs in the presence of LBD externalities. By doing so, it puts forward a rationale for why CFMs can be a useful part of the toolkit to manage the consequences of capital flows. It has done so through a parsimonious model but future research should consider also the interactions of LBD with other externalities as well as the role of other policies in an integrated fashion. 


\section{REFERENCES}

[1] Acosta, P. A., Lartey, E. K. K., and Mandelman, F. S., 2009. "Remittances and The Dutch Disease" Journal of International Economics, 79(1):102-116.

[2] Adrian, T., Erceg, C., Lindé, J., Zabczyk, P., and Zhou, J., 2020. "A Quantitative Model for the Integrated Policy Framework" IMF Working Paper 20/122, International Monetary Fund, July 2020.

[3] Arellano, C., 2009. “The Dynamic Implications of Foreign Aid and Its Variability." Journal of Development Economics, 88(1):87-102.

[4] Basu, S., Gopinath, G., Roch, F., and Unsal, F., 2020. "A Conceptual Model for the Integrated Policy Framework” IMF Working Paper 20/121, International Monetary Fund, July 2020.

[5] Benigno, G., Converse, N., and Fornaro, L., 2015. "Large capital inflows, Sectoral Allocation, and Economic Performance.” Journal of International Money and Finance, 55, 60 - 87, Macroeconomic and financial challenges facing Latin America and the Caribbean after the crisis.

[6] Bergant, K., Grigoli, N., Hansen, N. J. H., and Sandri, D., 2020. "Dampening Global Financial Shocks: Can Macroprudential Regulation Help (More than Capital Controls)?” IMF Working Paper 20/106, International Monetary Fund, June 2020.

[7] Bianchi, J., 2011. "Overborrowing and Systemic Externalities in the Business Cycle." American Economic Review 101 (7): 3400-3426.

[8] Blanchard, O., 2018. "On the Future of Macroeconomic Models." Oxford Review of Economic Policy (34: 1-2): 43-54.

[9] Caballero, R., and Lorenzoni, G., 2014. "Persistent Appreciations and Overshooting: A Normative Analysis.” IMF Economic Review, Palgrave Macmillan;International Monetary Fund, vol. 62(1), pages 1-47, April.

[10] Carrière-Swallow, Y., Magud, N.E., and Yépez, J. F., 2021. "Exchange Rate Flexibility, The Real Exchange Rate, and Adjustment to Terms-of-Trade Shocks." Review of International Economics. 2021; 00: 1- 45.

[11] Cooper, R., and Johri, A., 2002. "Learning-by-Doing and Aggregate Fluctuations." Journal of Monetary Economics, 49(8):1539-1566.

[12] Erten, B., Korinek, A., and Ocampo, J. A., 2021. "Capital Controls: Theory and Evidence." Journal of Economic Literature, 59 (1): 45-89.

[13] Farhi, E., and Werning, I., 2014. "A Theory of Macroprudential Policies in the Presence of Nominal Rigidities.” Econometrica 84 (5): 1645-1704.

[14] Fernández, A., Klein, M. W., Rebucci, A., Schindler, M., and Uribe, M., 2016. "Capital Control Measures: A New Dataset.” IMF Economic Review, 64 (3): 548-574. 
[15] Forbes, K. J., and Warnock, F. E., 2012. "Debt- and Equity-Led Capital Flow Episodes.” NBER Working Paper No. 18329 (Cambridge, MA: National Bureau of Economic Research).

[16] Forbes, K. J., Fratzcher, M., and Straub, R., 2015. "Capital Flow Management Measures: What Are They Good For?” NBER Working Paper No. 20860 (Cambridge, MA: National Bureau of Economic Research).

[17] Fratzcher, M., 2012. "Capital Flows, Push Versus Pull Factors and The Global Financial Crisis." Journal of International Economics, 88 (2): 341-356.

[18] García-Cicco, J., and Kawamura, E., 2015. "Dealing With the Dutch Disease: Fiscal Rules and Macro-Prudential Policies." Journal of International Money and Finance, Vol. 55: 205-239.

[19] Ilzetzki, E., Reinhart, C., and Rogoff, K., 2017. "Exchange Arrangements Entering the 21st Century: Which Anchor Will Hold?” NBER Working Paper No. 23134 (Cambridge, MA: National Bureau of Economic Research).

[20] Jarociński, M., and Karadi, P., 2020. "Deconstructing Monetary Policy Surprises-The Role of Information Shocks.” American Economic Journal: Macroeconomics, 12 (2): $1-43$.

[21] Kalemli-Özcan, S., 2019. "U.S. Monetary Policy and International Risk Spillovers." NBER Working Paper No. 26297 (Cambridge, MA: National Bureau of Economic Research).

[22] Kitano, S., 2011. “Capital Controls and Welfare.”Journal of Macroeconomics, Volume 33, Issue 4: 700-710.

[23] Kojo, N.C., 2014. “Demystifying Dutch Disease.” Policy Research Working Paper 6981, The World Bank Group.

[24] Kolasa, M., and Wesolowski, G., 2020. "International Spillovers of Quantitative Easing.” Journal of International Economics, Volume 126, September 2020, 103330.

[25] Krugman, P., 1987. "The Narrow Moving Band, the Dutch Disease, and the Competitive Consequences of Mrs. Thatcher.” Journal of Development Economics 27 (1-2): 41-55.

[26] Lama, R., and Medina, P., 2012. "Is Exchange Rate Stabilization an Appropriate Cure for The Dutch Disease.” International Journal of Central Banking. 8(1): 5-46.

[27] Lartey, E. K. K., 2008. "Capital Inflows, Dutch Disease Effects, and Monetary Policy in a Small Open Economy." Review of International Economics, 16(5):971-989.

[28] Lawrence, J. K., Eichenbaum, E., and Trabandt, M., 2018. “On DSGE Models.” Journal of Economic Perspectives (32: 3): 113-140.

[29] Lucas, R.J., 1976. "Econometric Policy Evaluation: A Critique.” Carnegie-Rochester Conference Series on Public Policy, 1(1):19-46, January 1976. 
[30] Magud, N.E., and Sosa, S., 2013. "When and Why Worry About Real Exchange Rate Appreciation? The Missing Link between Dutch Disease and Growth.” Journal of International Commerce, Economics and Policy. 4(02): 1-27.

[31] Milesi-Ferretti, G. M., and Tille, C., 2011. "The Great Retrenchment: International Capital Flows during the Global Financial Crisis.” Economic Policy, Vol. 26. No. 66, pp. 285-342.

[32] Miniane, J., and Rogers, J.H., 2007. "Capital Controls and The International Transmission of U.S. Money Shocks.” Journal of Money, Credit and Banking, 39(5):1003-1035, 2007. ISSN 1538-4616.

[33] Rajan, R., and Subramanian, A., 2011. "Aid, Dutch disease, and manufacturing growth." Journal of Development Economics 94 (1): 106-118.

[34] Reis, R., 2013. “The Portuguese Slump and Crash and the Euro Crisis.” Brookings Papers on Economic Activity, pp. 143-193.

[35] Rey, H., 2013. "Dilemma not Trilemma: The Global Financial Cycle and Monetary Policy Independence." in Proceedings of the Federal Reserve Bank of Kansas City Economic Symposium at Jackson Hole.

[36] Romer, P., 1986. "Increasing Returns and Long-Run Growth.” Journal of Political Economy, 94(5):1002-37.

[37] Runkle, D.E., 1987. "Vector Autoregressions and Reality.” Journal of Business and Economic Statistics, 5(4):pp. 437-442, 1987.

[38] Schmitt-Grohé, S., and Uribe, M., 2003. "Closing Small Open Economy Models.” Journal of International Economics, 61(1):163-185.

[39] Schmitt-Grohé, S., and Uribe, M., 2004. "Solving Dynamic General Equilibrium Models Using a Second-Order Approximation to The Policy Function.” Journal of Economic Dynamics and Control, 28(4):755-775.

[40] Schmitt-Grohé, S., and Uribe, M., 2016. "Downward Nominal Wage Rigidity, Currency Pegs, and Involuntary Unemployment." Journal of Political Economy 124 (5): $1466-1514$.

[41] Saffie, F., Varela, L., and Yi, K. M., 2020. "The Micro and Macro Dynamics of Capital Inflows.” NBER Working Paper No. 27371 (Cambridge, MA: National Bureau of Economic Research).

[42] Shin, H. S., 2012. "Global Banking Glut and Loan Risk Premium.” Mundell-Fleming Lecture, IMF Economic Review Vol. 60, No. 2, pp. 155-92.

[43] Tornell, A., and Westermann, F., 2005. "Boom-Bust Cycles and Financial Liberalization.”CESifo Book Series.

[44] Towbin, P., and Weber, S., 2013. "Limits of Floating Exchange Rates: The Role of Foreign Currency Debt and Import Structure.” Journal of Development Economics, 101: 179-194. 
[45] Uribe, M., and Yue, V. Z., 2006. "Country Spreads and Emerging Countries: Who Drives Whom?" Journal of International Economics, 69(1):6-36.

[46] Van Wijnbergen, S., 1984. “The 'Dutch Disease': A Disease After All?’Economic Journal 94 (373): 41-55.

[47] Wu, J. C., and Xia, F.D., 2016. "Measuring the Macroeconomic Impact of Monetary Policy at the Zero Lower Bound." Journal of Money, Credit, and Banking, 48(2-3). 